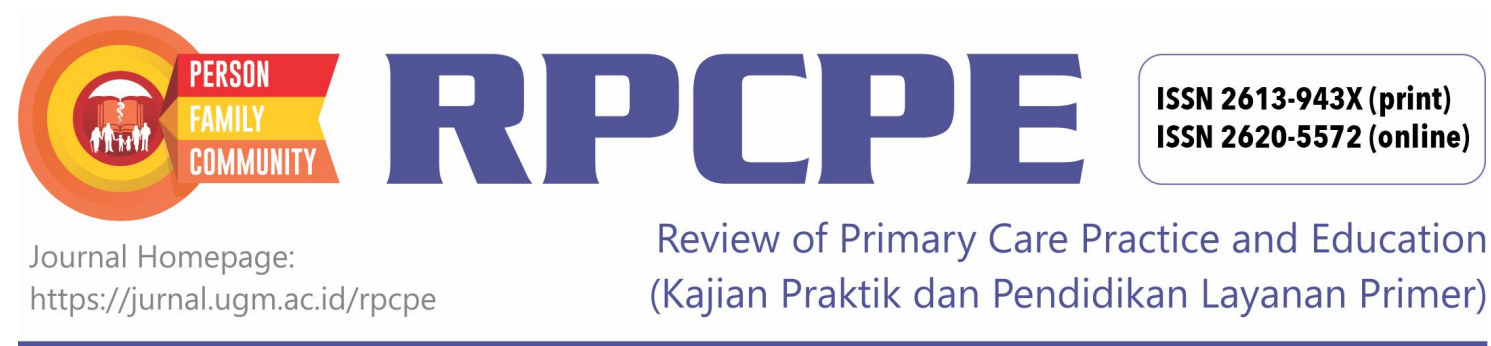

\title{
Analysis of Determinant Factors of Low Exclusive Breastfeeding Practice in Urban Slum Community of Surabaya
}

\author{
Hanna Tabita Hasianna Silitonga ${ }^{1}$, Abigail Elsha Tiara Susanto², Nadya Refina Tiurlan Barasa ${ }^{2}$ \\ ${ }^{1}$ Department of Public Health and Humaniora; Medical Faculty; Universitas Ciputra; Indonesia \\ 2 Student of Medical Faculty of Universitas Ciputra; Indonesia \\ Corresponding Author: \\ Hanna Tabita Hasianna Silitonga: Department of Public Health \& Humaniora, Medical Faculty of Universitas Ciputra, Surabaya, \\ CitraLand CBD Boulevard Surabaya - 60219, Indonesia \\ E-mail: hanna.silitonga@ciputra.ac.id
}

To cite this article:

Silitonga HTH, Susanto AET, Barasa NRT. Analysis of determinant factors of low exclusivebreastfeeding practice in urban slum community of Surabaya: A case study. Rev Prim Care Prac andEduc. 2019; 2(2): 60-65.

\begin{abstract}
Background: The World Health Organization's recommendation for infant feeding is exclusive breastfeeding for the first six months followed by semi-solid food. The purpose of the study is to analyse determinant factors related to low exclusive breastfeeding's practice in the urban slum community of Surabaya. Methods: This is a qualitative study with a case study in one of the urban slum areas of Surabaya. Data were collected by in-depth interviews and focus group discussion (FGD) with mothers, interviews with keyinformants; posyandu cadre and the community leader for validation. Ishikawa diagram tool was used to identify and categorize determinant factors. The Urgency, Seriousness, Growth (USG) method was used to prioritize factors. Results: There are 9 determinant factors categorized into 5 categories; two 'main' factors, three 'method' factors, two 'material' factors, one 'money' factor and one 'environment' factor. The one factor that was considered the priority to be resolved is from the environmentfactor that is local beliefs of breastfeeding and expressed breast milk. Discussions and Conclusions: Education of mothers about expressed breast milk is an initial step to overcome low exclusive breastfeeding's practice in this community due to mothers having to work outside the house. There is also a need for strengthening support groups so working mothers continuously exclusive breastfeed and provide optimal nutrition for infants.
\end{abstract}

Keywords: exclusive breastfeeding, determinant, urban, slum

\section{INTRODUCTION}

The provision of food to infants and children recommended by experts and the World Health Organization (WHO) is exclusive breastfeeding for 6 months and continued until the age of 2 years. After 6 months, breast milk must be combined with additional food. Breastfeeding in the first six months is crucial to achieving optimal growth and development. Breast milk also contains adequate nutrition and antibodies to prevent infants from contagious diseases such as diarrhoea and pneumonia and plays a very important role in the future growth and development of children ${ }^{1}$. There is a close relationship between the child's histories of exclusive breastfeeding with the incidence of stunting ${ }^{2}$.

Unfortunately, not all infants get their rights to have exclusive breastfeeding for a variety of reasons and conditions. Globally, it can be said that only 2 out of 5 infants are exclusively breastfed ${ }^{3}$. In Indonesia, data in 2016 showed that only $29.5 \%$ of infants received exclusive breast milk until the age of 6 months and the percentage of infants received breast milk in less than 6 months was $54 \%{ }^{4}$. From the same data, it was found that the percentage of infants who received breast milk for up to 6 months in East Java Province was $31.3 \%$. One of the cities in East Java is Surabaya. According to data from Surabaya Health Office in 2016 , there were $65.1 \%$ of infants who received exclusive breastfeeding, a $0.11 \%$ enhancement from the previous year ${ }^{5}$. This shows that there is an increase in health awareness and behaviour regarding the importance of exclusive breastfeeding even though there is no detailed data on this matter.

Surabaya is a densely populated city. One reason for 
population growth in cities is urbanization. This results in an increase in the need for housing or shelter. Unplanned settlements in major cities in Indonesia, including Surabaya, are often referred to as villages ${ }^{6}$. Villages that appear as informal settlements without infrastructure development such as regulations concerning buildings and facilities that meet basics needs, plus a dense population, are settlements that are not suitable for habitation and can be categorized into settlements or slums ${ }^{7}$.

Regarding health, many health problems can arise from slums, such as infectious diseases, malnutrition and various other diseases caused by low hygiene behavior. Research in the slums in Lucknow, India shows that the problem of malnutrition is due to the poor practice of feeding and vaccination, making children living in this area vulnerable to acute respiratory infections, diarrhea, worms, and vitamin deficiencies ${ }^{8}$.

A preliminary study in one of the slum settlements in Surabaya found that out of 45 children under five in this area, 6 children suffered from mild malnutrition and 2 children suffered from severe malnutrition. Another concern that was found was that most mothers did not breastfeed their children exclusively. This research was conducted to find the root of the problem of the low practice of exclusive breastfeeding in this community so as to get a picture of the problem and provide input for further research.

\section{RESEARCH METHODS}

This study used a qualitative approach with methods of in-depth interviews and focus group discussions (FGD) in one of the slums in Surabaya ${ }^{9}$. This community (kampung) was settled under the flyover. In-depth interviews were conducted with 2 mothers and 1 caregiver who had infants under one year. FGD was conducted with 10 mothers who had toddlers. Validation was done by comparing data obtained with data from Integrated Service Post/Pos Layanan Terpadu (posyandu) cadre as key-informants. Information about the community was obtained from one of the community leaders. The data were categorized using the Ishikawa fishbone diagram and then based on the USG method. The research team determines the priority issues to be resolved and these became the subjects of discussion and recommended suggestions.

\section{RESULTS}

\section{Characteristics of Area}

This kampung was located under the Dupak flyover. This area is not recognized legally but according to the community leader, there has been an unwritten agreement between the Surabaya's government and the residents regarding the existence of the place that the land in this kampung can be used without being charged for an unspecified time. Once the government needs this land, the residents must be ready to leave this area. This allows the kampung to still exist until now.

Most of the houses were made from woods and built close one to another. There were many piles of garbage all over the place because most of the population are scavengers.

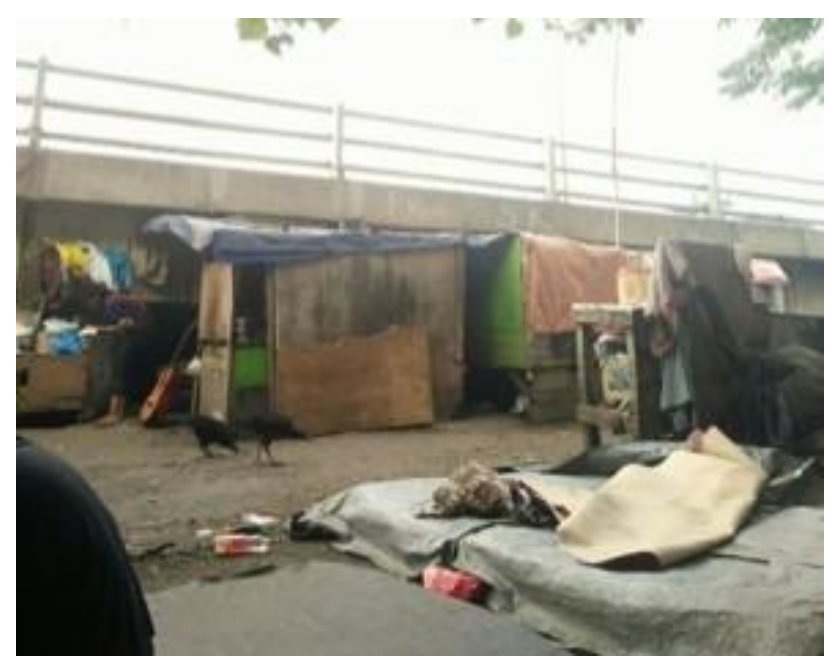

Picture 1. Kampung settled under the flyover

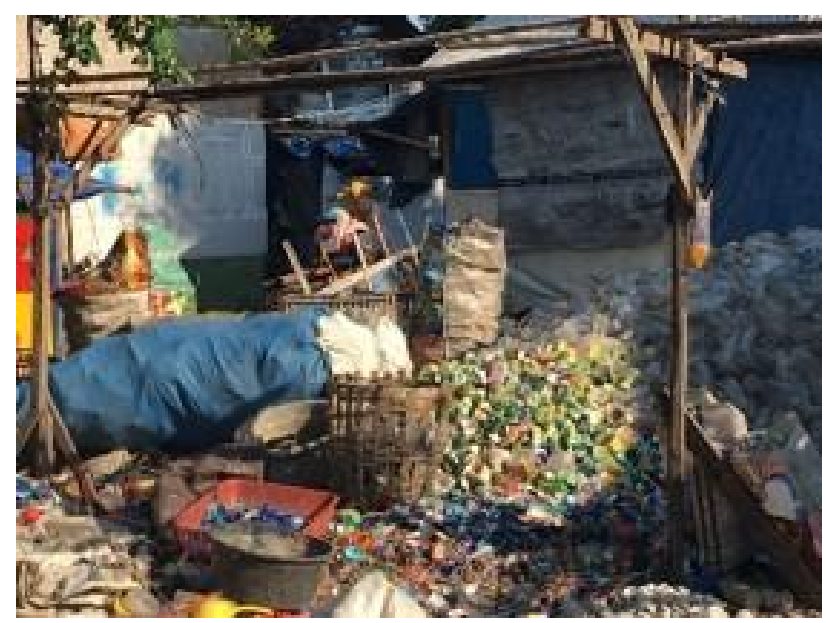

Picture 2. Garbage near the house

Another characteristic of this area is poor of public facilities for example clean water, where people have to buy water from near villages, poor road connectivity and also narrow walking space.

\section{Characteristics of Community}

According to the community leader, there are approximately 250 households in this area. The majority of residents in this village are from outside of Surabaya and do not have identity cards. Most of them have little to low income. Majority of the population are scavengers but there are also those who work in factories or have small businesses such as stalls. This community does not have a government structure like the head of the village even though they have people who are considered the leaders or elders in this area.

\section{Characteristics of Participants}

Characteristics of in-depth interview participants can be seen in Table 1. For the FGD, all 10 mothers are at 20-30 years of age. Key informants which from the posyandu cadre include a woman who is 24 years old with 3 children and a full-time housewife.

\section{Exclusive Breastfeeding Practice}

Of the two mothers and one caregiver interviewed they 
Table 1: Characteristic of in-depth interview participants

\begin{tabular}{lccc}
\hline \multicolumn{1}{c}{ Variable } & II01 & II02 & II03 \\
\hline Age (y.o) & 25 & 31 & 24 \\
Status/ & Mother & Aunt & Mother \\
Activity/occupation & Scavenger & Caregiver & Informal teacher \\
Marital status & Married & Married & Married \\
Number of children & 2 & 1 & 1 \\
Baby's age (month) & 0,5 & 2 & 2.5 \\
\hline
\end{tabular}

admitted that they did not practice exclusive breastfeeding. Two of mothers were giving breast milk at birth and formula milk later. Most reasons were they have to leave their children while they go to work.

"My new-born baby is still routinely breastfeeding, but if I work, I replace it with $\mathrm{S}^{* *}$ milk. My bigger child is 3 years old, just drink sugar water because the money will not be enough for buying milk for both of them." (II01)

One of the mothers did not breastfeed her baby since birth because she has Hepatitis and doctor did not allow her to breastfeed her baby.

"She didn't breastfeed because she had hepatitis, so the doctor prohibited her from breastfeeding. The baby is now given formula milk, already from birth. But now his mother has recovered, so she tries again to breastfeed but the baby doesn't want to, because it might be unusual. So finally formula milk continues.” (II02)

When asked about breast milk extraction, whether to use hand express or breast pump, two of the three participants never did it before because they were afraid that the breasts would explode if they pumped.

"No, I didn't dare. Some say that if you pump, your breasts can explode."(II01)

One of three participants did the breast milk extraction when she has to work and store milk in the freezer belonging to the posyandu cadre but it does not last long.

"Sometimes it is pumped and stored in cadre's freezer, but it is difficult for a long time." (II03)

From the FGD with mothers who had toddlers, all of the mothers were not breastfeeding their baby exclusively for the first 6 months. There is one mother who says that she does not give breast milk because the breast will be deflated if she continues to breastfeed.

"Breast can be deflated if it keeps going, so I just used formula milk."

In addition, from the FGD it is found that the pump is not an option that is commonly used by mothers in this area.

'It is unusual. Where will you store it? We don't have a freezer. It's possible to keep it in the cadre's place, but the house isn't close too."

"All I know is the pump could cause breast cancer."

\section{Determinant Factors}

From the interview results, there are several aspects that become the determinant factors of the low level of exclusive breastfeeding practice in this area. Using the Ishikawa diagram, the results are categorized into five categories. The Ishikawa fishbone diagram is shown in Figure 3.

\section{a. Main-factor}

Main factors are classified into mothers of infants and also caregivers who care for infants when the mother goes to work. From the interviews, it was found that the level of knowledge and attitudes towards exclusive breastfeeding of mothers and caregiver was good because mothers knew how long their infant should be given breast milk and the benefits obtained from breast milk.

From the interview, it was found that when the mother left for work, the baby would be entrusted to be guarded by their sister, called ' $b u$ 'dhe', the term for aunt.

"If I work, her bu' dhe usually take care of the baby." (II03)

A mother who gives her baby to the caregiver is mostly for work reasons. Mothers can leave home in the morning before the baby wakes up and then she returns at noon. During the time the caregivers take care of the infants. The caregiver's job is to keep the baby safe and also to give milk. Milk used is formula milk. This is because giving formula milk is considered practical. As obtained from observations that giving formula milk only used drinking water (not heated), which was placed in a milk bottle and shaken. Then formula milk is ready to be consumed by the baby.

From interviews, it was also found that both mothers and caregivers did not have problems using formula milk. When asked about pumping or expressing breast milk, two of the three participants refused to express milk.

\section{b. Method Factor}

Expressing breast milk is a solution for mothers who work outside the house to maintain the level of exclusive breastfeeding to infants. From the interview, it was found that mothers did not want to express breast milk. The cause of this is because they don't have knowledge and experience about express breast milk. Most of them answered never and did not know how to do it.

Another aspect in term of expressing breast milk is that there are negative perceptions about it. This is related to the local belief which becomes a personal perception that breast damage will occur when pumping or expressing 
breast milk.

"Just like a balloon, it can explode if it is pumped continuously." (II01)

On the other hand, the practical way of using formula milk also contributes to the low level of exclusive breastfeeding practices.

"It's easy. Just pour the water and stir." (II02)

From FGD we also found all mothers under five knew how to breastfeed correctly, but no mother had ever done breast pump or hand express breast milk and did not know how to do it.

\section{c. Economic Factor}

Other determinant factor that plays a role is economic problems. Families with low income make mothers have to work in supporting the family economy. This makes most mothers who are still in their productive age, have to go to work after giving birth and leave the baby. The work of the participants includes an informal teacher, factory worker, buskers, and scavengers.

\section{d. Material Factor}

Another determinant factor contributing to the low practice of exclusive breastfeeding is the availability of infant formula at an affordable price in the society. Most mothers in this area use milk with the same brand. From the interviews, there were mothers who had good knowledge about exclusive breastfeeding. Some mothers also pumped while working, but the biggest obstacle for the mother was not having a freezer. This resulted in the mother having to entrust her milk to neighbors who have a freezer and the fresh condition did not last long.

"Sometimes it is pumped and stored, but it is difficult for a long time ..." (II03)

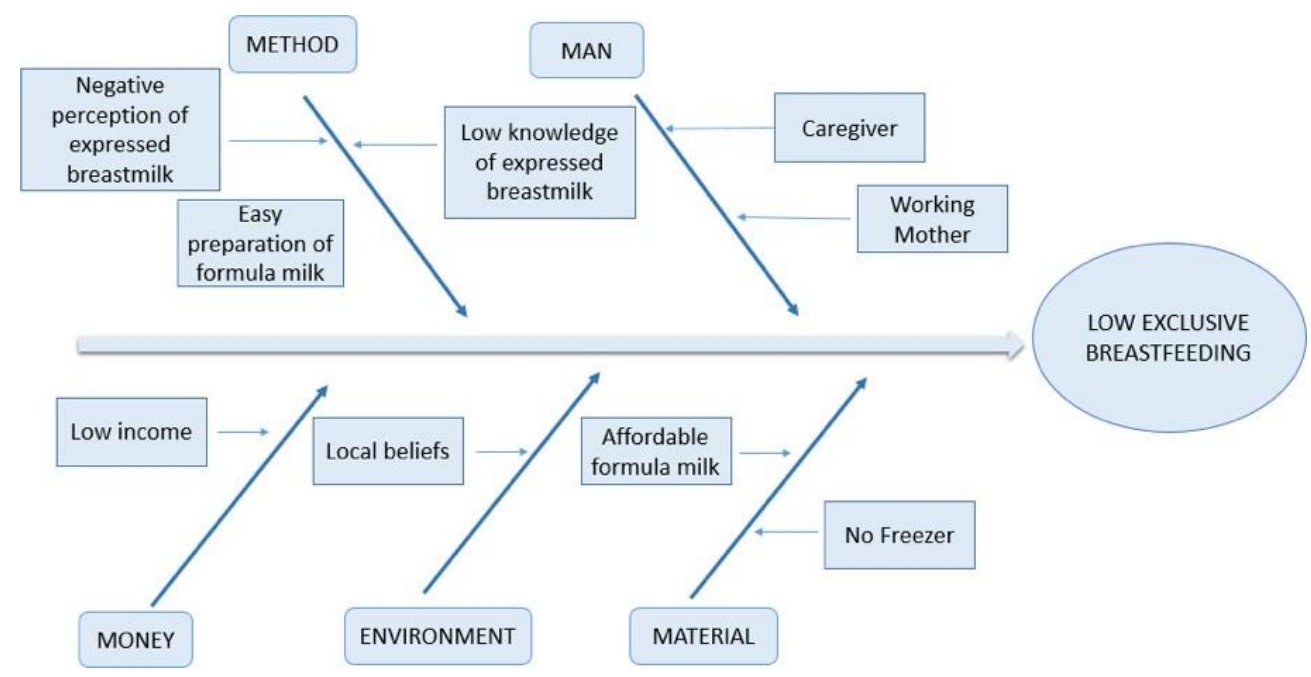

Picture 3. Ishikawa Fishbone Diagram

\section{e. Environmental Factor}

The local belief among mothers regarding breastfeeding and pumps is an obstacle to exclusive breastfeeding. They are afraid that if they breastfeed, their breasts will be flat and when pumped continuously, the breasts will explode like balloons and become cancerous. This is supported by the statement of the posyandu cadre who said,

"Indeed, mothers here are afraid of breastfeeding because of that ... It's been a long time."

This factor makes mothers prefer to give formula milk to their children rather than breastfeeding or pumping.

\section{Efforts to Increase Exclusive Breastfeeding Awareness}

From interviews with posyandu cadres who have been cadre for 10 years in this community, mothers get counselling from health worker who came every month for posyandu activities. The number of people attending counselling can be up to 160 people.

"If counselling is usually from the health centre. We only provide a place. The theme can be different. Usually the counsellor asked us our need for the topic. Most of the topic had been given, except HIV/AIDS and the pregnant program."

From this information, we assumed that information about breastfeeding had been given to mothers although the detailed description of counselling was not obtained. This was justified by the mothers of the FGD participants, although some of them said they did not get information about expressed breast milk at their counselling.

"We get counselling from health workers. But I'm not sure about expressed breast milk before."

From the interview, it was also found that the task of posyandu cadres was to record under-five body weight and report to Puskesmas if they found a baby categorized as malnutrition, so they could be handled by health workers.

"The cadre has been there for 10 years. We are 5 people. Our job is to record the weight of a toddler, we continue to report it to the Puskesmas. Actually, this kampung does 
not belong to the working area of the Puskesmas but they still want to help all this time. It's just that it doesn't help funds. Like when a heavy baby is under the yellow line, I tell the Puskesmas. There, mother and child were provided with milk and extra food. So, there shouldn't be more infants who weigh less. Because it is the government's programme."

\section{Prioritize the Problem with USG Method}

After conducting interviews and compiling the fishbone, the researchers then made a table of USG (Urgency, Seriousness, and Growth) and a score with a range of score for each criterion ranging from 1-8.

Table 2. USG Method

\begin{tabular}{clccccc}
\hline No & \multicolumn{1}{c}{ Element } & U & S & G & UXSXG & U+S+G \\
\hline 1 & Working mother & 4 & 5 & 4 & 80 & 13 \\
2 & Caregiver & 4 & 5 & 4 & 80 & 13 \\
3 & Less knowledge of expressed breast milk & 5 & 5 & 5 & 125 & 15 \\
4 & The negative perception of expressed breast milk & 5 & 5 & 5 & 125 & 15 \\
5 & Easy preparation formula milk & 4 & 3 & 3 & 36 & 10 \\
6 & No freezer & 4 & 4 & 4 & 64 & 12 \\
7 & Affordable formula milk & 4 & 5 & 6 & 120 & 15 \\
8 & Low income & 4 & 5 & 4 & 80 & 13 \\
9 & Local belief & 6 & 6 & 5 & 180 & 17 \\
\hline
\end{tabular}

From the process of prioritizing, the researchers agreed that the root cause of low exclusive breastfeeding in this community is the local belief about pumping or expressing breastmilk that had affected the personal perceptions of working mothers among the community. If local belief could be clarified, hopefully, the low knowledge and perception about expressed breast milk will be changed and improved.

\section{DISCUSSIONS AND CONCLUSIONS}

\section{Exclusive Breastfeeding and Working Mother}

Exclusive breastfeeding for mothers in an urban slum is an ideal concept for the baby, the mother, and family. It is ideal for infants because breast milk is very beneficial for infants, especially for infants who live in slums who are susceptible to contagious disease. Breast milk will provide a protective effect on infants. It is ideal for mothers because it also provides benefits to delay the next pregnancy for at least 6 months of exclusive breastfeeding. It is also ideal for family income, because breastfeeding will save expenses used to buy formula milk.

This justification was not obtained from this study. The majority factor is because the mother must work to contribute to the economic needs of the family. This in line with research made among working mothers in Dhaka slum that showed the mother's occupation had a broad impact on breastfeeding regularly and giving food to the children ${ }^{10}$. In Indonesia, this finding is in line with the research in the work area of Kawangkoan Community Health Centre which shows that there is a significant negative correlation between maternal statuses working with exclusive breastfeeding practices ${ }^{11}$.

Breastfeeding for working mothers should not be a problem if the mother knows about breastfeeding rights guaranteed by the state and also knows how to pump/express, store and use it. According to Government Regulation No. 33 of 2012 Article 30-35 states that management of workplaces and public facilities must support the implementation of exclusive breastfeeding practice through the existence of facilities and internal regulations ${ }^{12}$. Mothers who work in the formal sector can take advantage of this rule to earn the right to breastfeed and/or express breast milk. This is important because one study in Karnataka, India showed that some of the reasons why working mother didn't do exclusive breastfeeding were because there was a lack of facilities at the workplace to feed the baby ${ }^{13}$.

\section{Expressed Breast Milk}

Expressed breast milk could be done by hand express or breast pump using a tool either manually or electrically. Breast milk then should be stored in a clean container and freezer for long-term users. Breast milk could be stored short-term for 3-4 hours in a clean container and room temperature. Unfortunately, not all mothers know about this. The results of research in India regarding expressed breast milk found $60 \%$ of women have a negative perception about expressed breast milk. Some reasons for this are the lack of knowledge about this choice, and some are afraid to try it because they think it is too risky to store breast milk ${ }^{14}$.

The study conducted in the Puskesmas Air Dingin, Tanjung Aur Village showed that there was a relationship between maternal knowledge and the practice of expression breast milk $^{15}$. Another study in UPT Puskesmas II Denpasar Barat showed that $75 \%$ of working mothers succeed in exclusive breastfeeding due to the breast pump. The main factor of this success is an internal motivation to prepare expressed breast milk every day before going to work and pump regularly every 3 or 4 hours ${ }^{16}$.

On the other hand, a study conducted in Singapore and Hongkong showed that mothers who only fed the infants with expressed breast milk had tendency to terminate breastfeeding earlier than mothers who fed their infants directly at the breast ${ }^{17,18}$. Most of the studies show that 
woman who fed their infants with expressed breastmilk need more education and support so they can understand their choice and be consistent to do it.

\section{Sociocultural and Breastfeeding}

This study found that mother's negative perceptions toward expressed breast milk, in addition to lack of knowledge, involve a local belief that eventually becomes the internal value of mothers who are in this community. The outstanding belief that pumping/ hand express can cause breasts to rupture and cancer is a condition that may be missed by health workers. Meanwhile, unclean hands or pumping equipment can be a risk factor for mastitis which causes red, swollen, sore breasts due to infection of Staphylococcus aureus ${ }^{19}$. This problem might be assumed to be erupting and breast cancer. Maintaining hand hygiene and pumping equipment with soap and clean water could prevent this type of incident.

According to Kreuter and Haughton, the culture which includes what is learned, shared, passed on between generations and reflected in the values, beliefs, norms, and behaviours of the community, can be related to good behaviour directly and indirectly ${ }^{20}$. One model that can explain the case in this village is the folk theory. The folk theory states that people's behaviour are enforced by informal social controls like gossip and ridicule ${ }^{21}$. Folkways were approved by society and become repetitive action and could be internalized in personal action. Personal experiences can modify these folk models and thus influence that individual's behaviour ${ }^{20}$. An example of this matter could also be found in a study of mothers in Kenya who expressed and discarded their breast milk when the mothers were ill to relieve discomfort from engorgement ${ }^{22}$.

From the results, it was also found that the level of knowledge of mothers in this community about exclusive breastfeeding was good enough. This is likely due to routine counselling held at the posyandu with the help of health workers from the nearest puskesmas. Each counseling session was attended by approximately 160 mothers. Topics about exclusive breastfeeding had been presented by cadres and health workers. This shows that the knowledge of exclusive breastfeeding by mothers in the village is sufficient, but knowledge of expressed breastmilk has never been fully obtained.

From this study, it was concluded that the knowledge and skills of mothers towards exclusive breastfeeding in this community were sufficient but there were negative perceptions about expressed breast milk because it was influenced by the low level of knowledge and local beliefs about expressed breast milk which became obstacles to express breast milk in this community. Promotion and demonstration about expressed breast milk are needed to help mothers who had a negative perception, turning them to the positive perception of expressed breast milk. Intensive assistance, not just mass counselling, is also expected to help working mothers continue to do exclusive breastfeeding, the director expressed. Formation of breast milk cadres or improvement of posyandu cadre capacity related to this matter can be considered to be one of the solutions in the future.

\section{REFERENCES}

1. World Health Organization (WHO). 10 facts about breastfeeding. 2017 [Update on August 2017]. Available from: https://www.who. int/features/factfiles/breastfeeding/en/.

2. Ni'mah K, Nadhiroh SR. Factors associated with the incidence of stunting in infants. Indonesian Nutrition Media. 2016 Dec 22;10(1):13-9.

3. United Nations Children's Fund (UNICEF). Infant and young child feeding. 2018 [Update on July 2018]. Available from: https://data. unicef.org/topic/nutrition/infant-and-young-child-feeding/

4. Data and Information Centre. Indonesian health profile 2016. Jakarta: Ministry of Health Republic of Indonesia. 2017.

5. Surabaya City Health Office. Surabaya city health office profile in 2016. Surabaya: Surabaya City Health Office. 2016.

6. Nursyahbani R, Pigawati B. Study of slum settlements characteristic in urban villages (case study: Kampung Gandekan Semarang). Urban and Regional Planning. 2015 May 5;4(2):267-81.

7. Republic of Indonesia. Act number 1/2011 about housing and settlement areas. State Gazette of Republic of Indonesia. 2011(7).

8. Aggarwal T, Srivastava S. Nutritional status and its correlates in under five children of labor population in urban slums of Lucknow, Uttar Pradesh, India. Int J Contemp Pediatr. 2017 Jul;4:1253-8

9. Widyastuti W, Claramita M, Padmawati RS. Study of acceptance and application of calgary cambridge communication guideline for doctor-patient communication in primary health care. Review of Primary Care Practice and Education (Kajian Praktik dan Pendidikan Layanan Primer). 2018;1(3):123-8.

10. Kabir A, Maitrot MR. Factors influencing feeding practices of extreme poor infants and young children in families of working mothers in Dhaka slums: A qualitative study. PloS One. 2017 Feb 16;12(2):e0172119.

11. Timporok AG, Wowor PM, Rompas S. Relationship between the mother work status and exclusive breastfeeding in the working area of the Puskesmas Kawangkoan. Nursing Journal. 2018 Apr 27; 6(1).

12. Government Ordinance. Government ordinance number 33/2012 about exclusive breastfeeding. Jakarta: State Secretariat. 2012.

13. Boralingiah P, Polineni V, Kulkarni P, Manjunath R. Study of breastfeeding practices among working women attending a tertiary care hospital, Mysore, Karnataka, India. International Journal of Community Medicine and Public Health. 2017 Feb 3;3(5):1178-82.

14. Rai S. Expressed breast milk: A less used option by working mothers of India. International Journal of Reproduction, Contraception, Obstetrics, and Gynecology. 2017 Jul;6(7):2867-2873.

15. Harfiandri S, Dea D, Putri A. Relationship of education and knowledge of the mother about breast milk with practice of breastfeeding. Endurance Journal: Scientific Study of Health Problems. 2018 Jun 29;3(2):415-21.

16. Martini NK, Astuti NP. The driving factors of mother in providing exclusive breastfeeding at UPT Puskesmas II Denpasar Barat. Integrated Health Journal. 2017 Mar 31;1(1).

17. Bai DL, Fong DY, Lok KY, Wong JY, Tarrant M. Practices, predictors and consequences of expressed breast-milk feeding in healthy fullterm infants. Public Health Nutrition. 2017 Feb;20(3):492-503.

18. Pang W, Bernard J, Thavamani G, Chan Y, Fok D, Soh SE, et al. Direct vs. expressed breast milk feeding: Relation to duration of breastfeeding. Nutrients. 2017 Jun;9(6):547.

19. Spencer JP. Management of mastitis in breastfeeding women. Am Fam Physician. 2008 Sep 15;78(6):727-31.

20. Rosal MC, Bodenlos JS. Culture and health-related behavior. The Handbook of Health Behavior Change. 2009:19-37.

21. Gupta MC, Mahajan BK. Textbook of preventive and social medicine 4th ed: social environment. India: Jaypee Brothers Medical Publishers Ltd, 2013; p. 126-136.

22. Talbert AW, Tsofa B, Mumbo E, Berkley JA, Mwangome M. Knowledge of, and attitudes to giving expressed breastmilk to infants in rural coastal Kenya; focus group discussions of first-time mothers and their advisers. International Breastfeeding Journal. 2018 Dec;13(1):16. 